\section{Revisión, entorno y paso al frente}

\section{Margarita Taladriz-Mas} Presidenta de Fesabid (2010-2014)
mtaladrizmas@gmail.com

Taladriz-Mas, Margarita (2015). "Revisión, entorno y paso al frente". Anuario ThinkEPI, v. 9, pp. 102-103.

http://dx.doi.org/10.3145/thinkepi.2015.20

Publicado en Blok de BiD el 14 de mayo de 2014

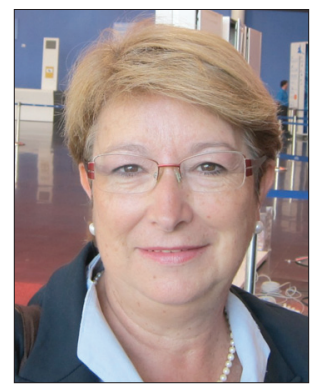

Pautas de servicios bibliotecarios para niños y jóvenes son el resultado del trabajo llevado a cabo por el Grupo de Trabajo de Servicios Bibliotecarios para niños $y$ jóvenes dentro de la dinámica del Consejo de Cooperación Bibliotecaria $(C C B)$ y presentado en la sesión del CCB de marzo de 2014.

Los resultados de este grupo de trabajo son un paso más allá en el análisis de las funciones que viene desempeñando la biblioteca pública, ya que se dedica en detalle a las necesidades de acceso a la información de un segmento concreto de población: los niños y los jóvenes. Además ofrece una cierta prospectiva de lo que sería necesario plantear para poder seguir cumpliendo las funciones que le son propias, de cara al futuro.

Se repasan los servicios tradicionales para este segmento de usuarios, pero se hace hincapié, con ese sentido de prospectiva, en otros tipos de actividades y servicios que se les deberían ofrecer,

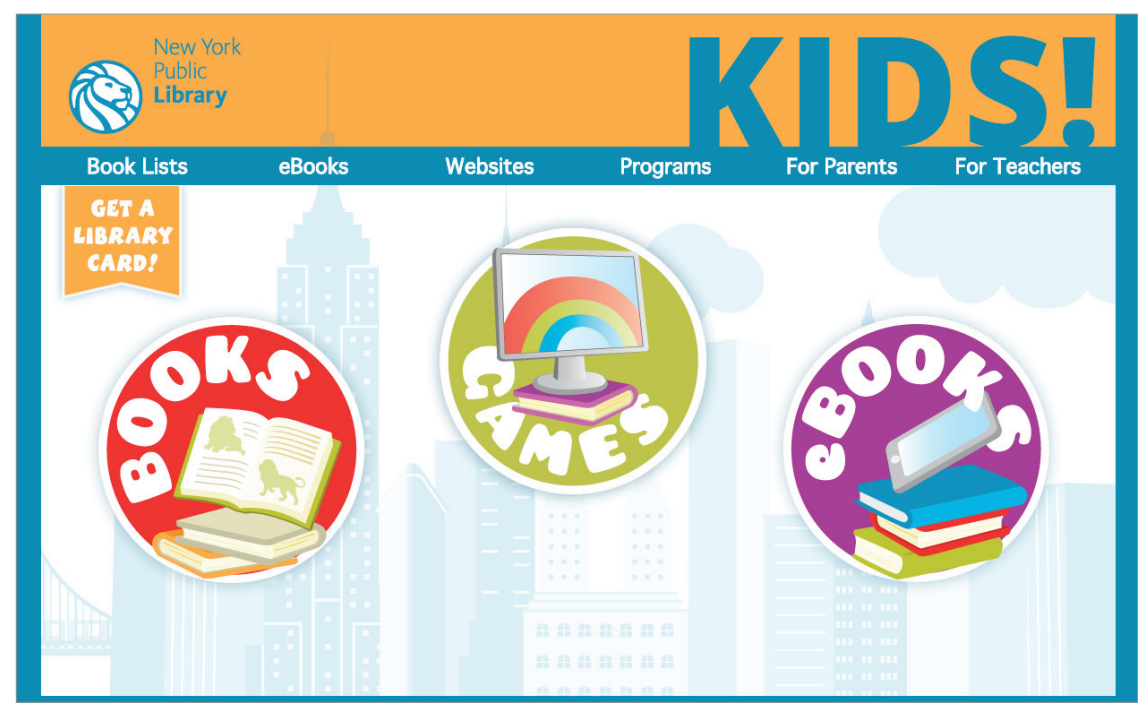

http://kids.nypl.org/index.cfm sobre todo a los jóvenes, si se quiere mantenerlos como usuarios.

Se presta una atención especial a los espacios diferenciados que debe proporcionar la biblioteca como lugar de encuentro para que los niños y los jóvenes, y también los adultos jóvenes, se los hagan suyos. Ellos incluso pueden colaborar en su reforma sugiriendo las posibles modificaciones, para adaptarlos a sus necesidades de centro social y de encuentros versátiles y multiformes.

De la lectura del informe se deduce que por lo que respecta a la sección infantil hay ya un gran camino andado, pero en el sector juvenil parece necesario hacer un mayor esfuerzo. En esta etapa los chicos comienzan a abandonar la lectura, por lo que se proponen servicios más adaptados a sus gustos, sin olvidar el fomento y apoyo a la lectura, entendida en su más amplio sentido: lectura digital, presencia en redes sociales, como punto de nexo y de participación, participación en la selección de recursos de información, espacios tecnológicos con acceso a software de aprendizaje y de ocio, códigos QR, aplicaciones para dispositivos móviles, etc.

Se insiste en la necesidad de incorporar a estos usuarios juveniles en las decisiones de gestión, para que sientan la biblioteca como propia: actividades que se programen e iniciativas que puedan desarrollar por sí mismos en el marco de la biblioteca "lo que les aportará valores de igualdad, responsabilidad y autonomía".

Se plantean dos temas de enorme interés:

- Especialización del personal que atiende este tipo de bibliotecas, que debe tratar unos usuarios extremadamente sensibles: niños y jóvenes. La capacidad de los bibliotecarios para hacerse cercanos y comprender sus necesidades y expectativas será imprescindible sí se quiere que la biblioteca pueda cumplir este objetivo. Puede buscarse la colaboración de otros profesionales del entorno: animadores y gestores culturales, tecnólogos, narradores orales...

- Marketing del servicio, elemento muy importante para que todos los esfuerzos que realiza la biblioteca lleguen a la sociedad en general $y$ a sus usuarios en particular.

Un punto fuerte de este trabajo es el análisis de buenas prácticas que se presenta en la última parte. Se analizan y comentan experiencias con niños y jóvenes de varias bibliotecas: 
- Biblioteca para Jóvenes Cubit, Zaragoza

- Internationale Jugendbibliothek München (International Youth Library), Alemania

- New York Public Library, EUA

- Biblioteca Medien@ge, Dresde, Alemania

- Mediateka, Breslau; y Planeta 11, Alenstein, Polonia

- Cable Book Library, Helsinki, Finlandia

- Teen'scape, Los Ángeles, EUA

- Biblitoteca de Phoenix, EUA

- Library Orchard, Singapur

- Sistema de Bibliotecas, Dinamarca

También se incluyen enlaces a revistas, webs de interés y blogs especializados en el sector. La bibliografía es amplia, actualizada e imprescindible con especial referencia a normativa y pautas de IFI A Unesco y Ministerio de Cultura

Este informe es un modelo de cómo plantear un trabajo de estas características, con sus tres fases diferenciadas: estado de la cuestión (Análisis), mirada al futuro (Paso al frente/prospectiva) y buenas prácticas (Entorno)

Sánchez-Torres, Luis (Coord.) 2013. Pautas de

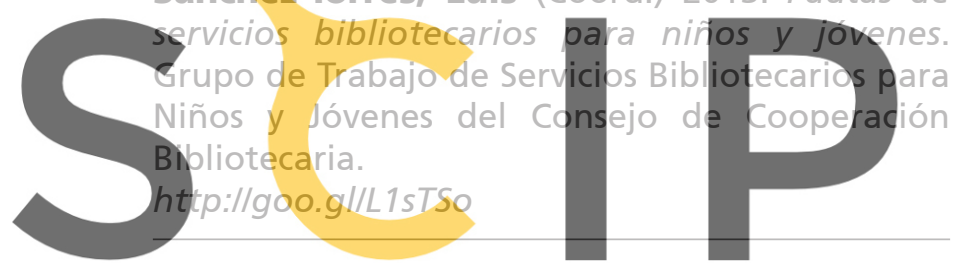

Nota original completa en Blok de BiD:

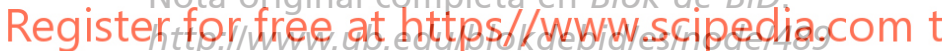

\section{Ithaka S+R US Library survey 2013}

\section{José-Antonio Magán-Wals}

Director de proyectos bibliotecarios, Universidad Complutense de Madrid magan@buc.ucm.es

Magán-Wals, José-Antonio (2015). "Ithaka S+R US Library survey 2013". Anuario ThinkEPI, v. 9, pp. 103-105.

http://dx.doi.org/10.3145/thinkepi.2015.21

Publicado en Blok de BiD el 18 de junio de 2014

El Ithaka $S+R$ US Library survey 2013 es el segundo de los informes que Ithaka, una fundación no lucrativa dedicada a promover el uso de las tecnologías digitales entre la comunidad

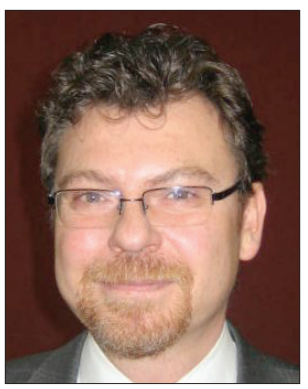

universitaria, ha realizado para analizar las opiniones de los responsables académicos de las bibliotecas académicas de Estados Unidos y de sus directores respecto a temas clave de su servicio. A partir de una encuesta enviada a la casi totalidad de las bibliotecas académicas y respondida por un tercio de ellas, el análisis de Matthew P. Long y Roger C. Schonfeld aporta datos muy interesantes respecto a las preocupaciones de los directivos de bibliotecas y de la evolución acaecida en los últimos años.

Para un buen número de las cuestiones planteadas se distingue, dada la diversidad de opiniones, entre bibliotecas de las grandes instituciones académicas, las de tamaño medio y las dedicadas a estudios de sólo grado. Así, la implicación de las bibliotecas en servicios novedosos que van más allá de las funciones tradicionales son considerablemente mayores en las pertenecientes a grandes instituciones. Entre el anterior informe de 2010 y éste se aprecia una disminución de la

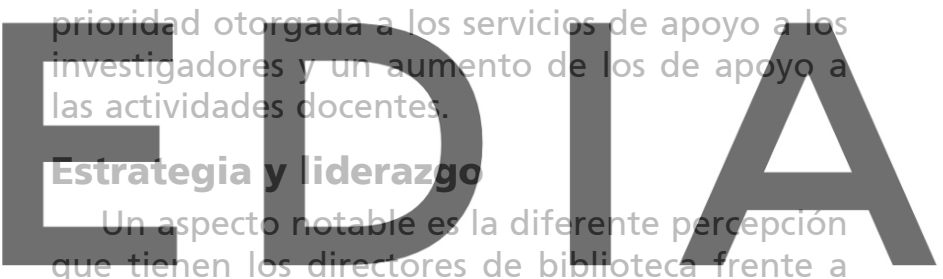

los responsables académicos respecto al papel

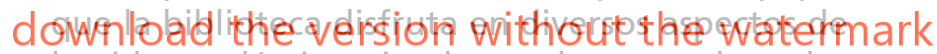

la vida académica, siendo por lo general mucho más optimista la visión de los bibliotecarios. Destaca la baja percepción que los académicos tienen de la biblioteca en relación a las labores de archivo o apoyo a la investigación. Sin embargo ambos colectivos coinciden en que el principal papel de la biblioteca estriba en la alfabetización informacional aunque los bibliotecarios se ven a sí mismos con un papel mucho más activo de lo que le reconocen sus responsables académicos respecto a su contribución al aprendizaje de los estudiantes en el uso de los recursos de información o de los gestores bibliográficos.

Menos de la mitad de las instituciones carecen de estrategias claramente definidas para atender los cambios en los hábitos de los usuarios, algo que

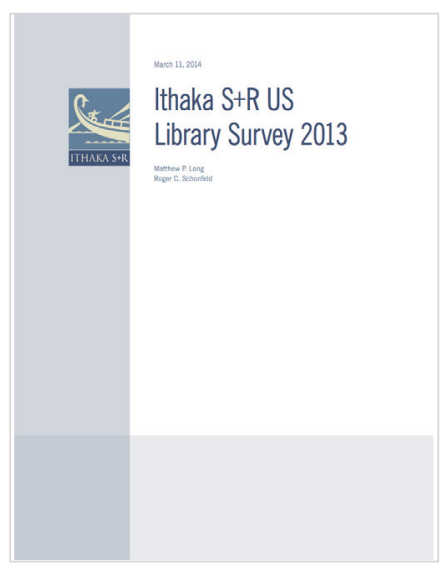

